\title{
SAPC hot topic - capacity for blue sky research in academic primary care
}

\author{
Joanne Reeve ${ }^{1}$ and Christian Mallen ${ }^{2}$ \\ ${ }^{1}$ NIHR Clinician Scientist in Primary Care, Department of Health Services Research, University of Liverpool, Liverpool, UK \\ ${ }^{2}$ Professor of General Practice, Arthritis Research UK Clinician Scientist, Arthritis Research UK Primary Care Centre, \\ Keele University, Staffordshire, UK
}

Key words: blue sky research; primary care

Received 9 April 2012; accepted 18 April 2012

'Is there a category of basic research in primary care?'

This opening question in Professor Graham Watt's (2011) report on blue sky research in primary care sends out both an invitation and a challenge to all working in academic primary care (APC). His report is a response to persisting concerns about a gap in the recognition of, and support for, this key aspect of research and development in primary care. Drawing on an extensive stakeholder consultation, Watt considers fundamental issues related to funding streams, professional identity, career planning and progression within our discipline. You can read the full report on the Society for Academic Primary Care website (http://www.sapc. ac.uk/images/documents/blue.pdf).

The specific remit for his report was to consider issues related to generalist clinical practice. But Watt's broader aim was to stimulate debate and discussion across the primary care research community. APC is underpinned by a multidisciplinary approach, necessary to promote excellence in the complexity and diversity of primary care policy and practice (Reeve et al., 2011). His report raises important questions for all working in, or connected to, our discipline. In this Hot Topic report, we focus on one aspect, namely, the capacity for blue sky research in our discipline.

Correspondence to: Dr Joanne Reeve, Department of Health Service Research, University of Liverpool, B122 Waterhouse Buildings, 1-5 Brownlow Street, Liverpool L69 3GB, UK. Email: joanne.reeve@liv.ac.uk

(C) Cambridge University Press 2012

\section{So what is blue sky research?}

Blue sky research refers to 'research without a clear goal' (Bell, 2005). Linden (2008) describes it as 'flexible, curiosity-driven research' underpinned by creative thinking that 'leads to outcomes not envisaged at the outset'. Blue sky research is characterised by development and proof of concept - concepts that can then be applied and evaluated for proof of worth and utility. It has been suggested that the inherently uncertain nature of blue sky research has made it 'politically and commercially unpopular' (Bell, 2005), although the value of this area of development is well recognised and established within many areas of medical research (Watt, 2011).

\section{Blue sky research in primary care}

Watt (2011) defines blue sky research in primary care as 'research which increases conceptual understanding of the content, processes, organisation and outcomes of primary care'. He acknowledges existing contributions, citing examples of completed work, but describes a need for further conceptual understanding of the behaviours, consultations and systems underpinning primary care in order to address gaps in this 'basic research' and thus better support the applied primary care research funded by bodies such as the National Institute for Health Research. The report offers specific examples of possible future areas of 


\section{Box 1 Examples of a basic primary care research agenda (Watt, 2011)}

Understanding the structure of the system(s) that make up primary care: including consideration of benefits and opportunity costs of change including workforce changes, and the addition of new activities and services to primary care. Understanding the 'active ingredients' of an 'intervention' that is primary care: including issues related to continuity of care, communication, collaborative care, generalist care.

Understanding the (needs of) the person who uses the primary care service: including consideration of how to integrate multiple perspectives on individual illness experiences/ responses offered by the basic sciences (including social sciences, psychology, economics); understanding variation in need and service use; and addressing medically undefined problems.

enquiry and research development within a field of blue sky primary care research (Box 1).

\section{Addressing gaps - an issue of funding?}

Watt (2011) suggests that blue sky research is integral to the critical development of the discipline. His key thesis is that, although basic, blue sky biomedical research is 'thoroughly supported' by research funding bodies, and that there is 'much less recognition and support for the equivalent stage in primary care research'. He thus suggests that inadequate external recognition and support for this area acts to limit capacity for blue sky thinking. His report seeks to prompt wider discussion about whether funding bodies could be more supportive in this area, with a principal objective being to "establish identity, recognition and support for the basic research needs of generalist clinical practice in the NHS'.

\section{So why haven't we had this conversation sooner?}

Blue sky research is necessary for the critical development of the discipline. So why is it only in
2011 that this report has been written? How is it that despite over five decades of work from academic departments of general practice and primary care those outside the discipline don't yet adequately recognise the importance and significance of this conceptual basic research?

Perhaps the answer lies, at least in part, in the historical development of the discipline. APC grew out of departments of academic General Practice as they joined forces with related disciplines. Staff in General Practice departments were balancing heavy teaching workloads with clinical commitments, alongside developing research. Particularly in comparison with some other clinical specialities, the time available for blue sky thinking was limited. As a young and emerging discipline, did we perhaps feel a need to focus on applied research that demonstrated the value and worth of both primary care and APC? In investing so much in the applied work, did we not have time for what seemed like a 'luxury' of blue sky thinking?

The problem may lie more fundamentally in the complexity and diversity of primary care. The Society for Academic Primary Care (SAPC) position statement (Reeve et al., 2011) acknowledges three perspectives on defining primary care. Primary care can be understood as an organisational model of healthcare delivery (a multidimensional system of care facilitating coordinated, continuous and equitable access to a range of services); a patient experience of care (as an accessible first point of contact with health care, providing comprehensive and continuous treatment for a range of problems); and a philosophy of health care (patient-centred care, supporting health as a resource for living). Defining core concepts across such a diverse domain is challenging. Researchers within the field have become increasingly specialised (Rosenthal et al., 2011); researchers and teachers have, in places, been separated by organisational reconfiguration. Is there a need to spend some time reconnecting within the discipline, recognising our shared concepts in order to better convey their importance to an external world?

Or perhaps we have felt that the conceptual work simply takes place elsewhere, with much of the blue sky thinking of APC found in professional accounts in the clinical setting or within its partner disciplines? Is APC seen as a mechanism 
to 'teach and test' conceptual accounts developed elsewhere, with no need for capacity for blue sky thinking? Such a position has significant implications for a view of APC as a 'distinct discipline' (Reeve et al., 2011), offering something over and above - for example - health services research in a primary care context. Could it be said that a capacity for blue sky thinking is integral and essential to the development and survival of the discipline?

Watt (2011) has started important conversations seeking to generate external support for capacity for blue sky thinking in primary care research. Perhaps we need also to think about how we can enhance this activity within the discipline itself. International comparisons now demonstrate that APC has 'come of age', which is evidenced in both the quality and volume of primary care research (Glanville et al., 2011). Perhaps maturity now brings both an opportunity and a requirement to be brave and make the space for this necessary creativity and scholarship.

\section{So how can we encourage capacity for blue sky thinking from within the discipline?}

At SAPC we are actively seeking to develop and support these critical, creative and shared conversations (http://www.sapc.ac.uk/index.php/festival-ofideas). For example, at this year's conference, we will be launching our new 'Dangerous Ideas Soapbox' (www.sapc.ac.uk/index.php/conference 2012/2012-programme-overview/dangerous-ideas). We have a dedicated slot in the programme for people to present and debate new ideas - an opportunity to give a voice to thoughts not usually featured at scientific meetings. The meeting will be run as a hustings - with the winner being invited to present their idea to a wider audience as a Hot Topic report, and on our website. The abstract deadline for the soapbox has passed, but do contact us if you have a good idea and we'll think about how we might incorporate it.

SAPC welcomes this important report and thanks Professor Watt for leading off these vital areas of discussion. We now invite you all to join us in continuing the critical, creative and shared conversations he has started. Join us in conversation on Facebook (www.facebook.com/ groups/209153699181141/), on our website (www. sapc.ac.uk) or by contacting us directly (joanne. reeve@liv.ac.uk or c.d.mallen@cphc.keele.ac.uk).

\section{References}

Bell, D. 2005: Science, technology and culture. Maidenhead: McGraw-Hill Education.

Glanville, J., Kendrick, A., McNally, R., Campbell, J. and Hobbs, F.D.R. 2011: Research output on primary care in Australia, Canada, Germany, the Netherlands, the United Kingdom, and the United States: bibliometric analysis. British Medical Journal 342, d1028.

Linden, B. 2008: Basic blue skies research in the UK: are we losing out? Journal of Biomedical Discovery and Collaboration 3, 3 .

Reeve, J., Salisbury, C., Fairhurst, K., Adams, A., on behalf of The SAPC Executive. 2011: The Society for academic primary care: position statement April 2011. Primary Health Care Research \& Development 12, 183-84.

Rosenthal, J., McKinley, B. and Pearson, D. 2011: Promoting Education within SAPC: introducing the HoTs group. Primary Health Care Research \& Development 12, 276.

Watt, G. 2011. Blue sky research for primary care: a discussion paper. Retrieved 09 April 2012 from http://www.sapc.ac.uk/ images/documents/blue.pdf 